\title{
Tryptophan Depletion Alters the Decision-Making of Healthy Volunteers through Altered Processing of Reward Cues
}

\author{
Robert D Rogers*,', Elizabeth M Tunbridge', Zubin Bhagwagar', Wayne C Drevets ${ }^{2}$, Barbara J Sahakian ${ }^{3}$ and \\ Cameron 5 Carter ${ }^{4}$ \\ 'University Department of Psychiatry, University of Oxford, Oxford, UK; ${ }^{2}$ Section on Mood and Anxiety Disorders Neuroimaging, National \\ Institute of Mental Health, NIH, Washington, DC, USA; ${ }^{3}$ University Department of Psychiatry, University of Cambridge, Cambridge, UK; ${ }^{4}$ Center \\ for the Neural Basis of Cognition, University of Pittsburgh, Pittsburgh, USA
}

\begin{abstract}
While accumulating evidence suggests that effective real-life decision-making depends upon the functioning of the orbitofrontal cortex, much less is known about the involvement of the monoamine neurotransmitter systems and, in particular, serotonin. In the present study, we explored the impact of depleting the serotonin precursor, tryptophan, on human decision-making. Eighteen healthy volunteers consumed an amino-acid drink containing tryptophan and 18 healthy volunteers consumed an amino-acid drink without tryptophan, before choosing between simultaneously presented gambles, differing in the magnitude of expected gains (ie reward), the magnitude of expected losses (ie punishment), and the probabilities with which these outcomes were delivered. Volunteers also chose between gambles probing identified non-nomative biases in human decision-making, namely, risk-aversion when choosing between gains and riskseeking when choosing between losses. Tryptophan-depleted volunteers showed reduced discrimination between magnitudes of expected gains associated with different choices. There was little evidence that tryptophan depletion was associated with altered discrimination between the magnitudes of expected losses, or altered discrimination between the relative probabilities with which these positive or negative outcomes were delivered. Risk-averse and risk-seeking biases were also unchanged. These results suggest that serotonin mediates decision-making in healthy volunteers by modulating the processing of reward cues, perhaps represented within the orbitofrontal cortex. It is possible that such a change in the cognition mediating human choice is one mechanism associated with the onset and maintenance of anhedonia and lowered mood in psychiatric illness.
\end{abstract}

Neuropsychopharmacology (2003) 28, I53-162. doi: I 0. I038/sj.npp. I30000 I

Keywords: tryptophan depletion; serotonin; decision-making; orbitotrontal cortex; risk-aversion and risk-seeking

\section{INTRODUCTION}

Research with neurological patients and brain-imaging technologies has demonstrated that the capacity to make effective real-life decisions, involving choices between actions leading to uncertain outcomes, depends upon the integrity of the orbitofrontal cortex and its interconnected neural circuitry (Bechara et al, 1996; Damasio, 1994; Rogers et al, 1999b, c). Recent extension of this work has suggested that deficits in the decision-making of psychiatric patients may involve dysfunction in the same neural machinery (Bechara et al, 2001; Rahman et al, 2001; Rogers et al, 1999b). Despite these advances, relatively little is known about how altered activity of the ascending reticular arousal

\footnotetext{
*Correspondence: Dr RD Rogers, University Department of Psychiatry, Warneford Hospital, Oxford OX3 7JX, UK, Fax: +44 1865793 I0I, E-mail: robert.rogers@psych.ox.ac.uk

Received 26 November 2001 ; revised 20 May 2002; accepted 20 June 2002

Online publication: 24 June 2002 at http://www.acnp.org/citations/ Npp062402336
}

systems influences decision-making, even though such information would help build a more complete picture of the principal neurochemical determinants of human choice, and improve our understanding of the cognitive effects of monoaminergic therapies. In a previous study, we found that rapid dietary tryptophan depletion-leading to reduced central serotonin function (Nishizawa et al, 1997) - impaired the decision-making of healthy volunteers (Rogers et al, 1999b). However, the complexity of the decision-making task used in that study precluded examination of the mechanisms that might have produced this result. In the present study, we used a novel decision-making procedure to reveal the impact of tryptophan depletion on separable factors known to determine human choice: specifically, the magnitude of expected gains (or reward), the magnitude of expected losses (or punishment), and the probabilities with which these outcomes are delivered (Goldstein and Hogarth, 1997).

There are several mechanisms by which altered serotonin function might modulate decision-making. According to 
theoretical perspectives that emphasise the role of serotonin in mediating anxiety (Deakin and Graeff 1991; Iversen, 1984; Gray, 1987) and the effective processing of aversive signals (Tye et al, 1977; Wilkinson et al, 1995), we might expect lowered serotonin to impair decision-making by inducing a failure to process expected losses adequately; that is, punishment cues might fail to generate anticipatory anxiety states associated with risky or maladaptive choices. Complementing this approach, the involvement of serotonin in behavioural suppression and control of 'punished' or 'nonrewarded' responding (Harrison et al, 1997, 1999; Soubrie, 1986) suggests that lowering serotonin may alter volunteers' decision-making by undermining their capacity to inhibit activated responses sufficiently in order to integrate aversive signals relevant to the imminent choice. For these reasons, we might predict that rapid tryptophan depletion will alter decision-making in healthy volunteers through altering their processing of expected losses.

By contrast, another perspective highlights the role of serotonin in modulating reinforcement and incentivemotivational processes, possibly through complex interactions with the mesolimbic dopamine system (Baumgarten and Grozdanovic, 1995) and the regulatory functions of several serotonin receptor subtypes (eg Parsons et al, 1996; Walsh and Cunningham, 1997). Evidence of a role for serotonin in reward processing includes recent demonstrations that the behavioural and reinforcing effects of cocaine in rats are potentiated by treatment with selective serotonin-reuptake blockers (SSRIs) (Cunningham and Callahan, 1991; Kleven and Koek, 1998; Sasaki-Adams and Kelley, 2001), and that brain self-stimulation thresholds can be dose-dependently altered with SSRI treatment (Harrison and Markou, 2001a,b). Also relevant are serotonin's acknowledged involvement in clinical depression (eg Schildkraut, 1965) and the more general observation that SSRI treatment is relatively effective in the treatment of clinical depressive illness, while the temporary reduction of central serotonin function in vulnerable individuals through rapid dietary tryptophan depletion has been shown to reinstate depressive symptoms and flat affect (Moore $e t$ al, 2000; Smith et al, 1997). Finally, depleted serotonin function within limbic structures associated with reward processing, such as the nucleus accumbens, has also been implicated as an important mediating factor in the affective/motivational aspects of withdrawal phenomena in drug-dependent individuals (Markou et al, 2001; Weiss et al, 1996).

In studies with healthy volunteers, serotonin also appears to play a role in affective learning and, in particular, in the effective acquisition of stimulus-reward linkages as evidenced by the finding that tryptophan depletion produces deficits in simultaneous visual discrimination and reversal learning studies (Park et al, 1994; Rogers et al, 1999a). Since reversal learning is believed to involve the orbitofrontal cortex (Dias et al, 1996; Jones and Mishkin, 1972; Thorpe et $a l, 1983$ ) - as does decision-making (Bechara et al, 1996; Rogers et al, 1999b, c) - serotonin may undermine decision-making through altering the representation of reward within the orbitofrontal cortex. Accordingly, we might predict that tryptophan depletion alters decision-making through a change in the processing of reward cues.

One way to study decision-making is to present volunteers with two 'gambles', each consisting of a given probability of winning a certain outcome or losing a certain outcome; for example, a choice between a $25 \%$ chance to win $\$ 100$ and a $75 \%$ chance of losing $\$ 20$ vs a $25 \%$ chance to win $\$ 240$ and a $75 \%$ chance to lose $\$ 60$. Variation in volunteers' preferences, as determined by differences between magnitudes of gains and losses in each gamble, as well as their respective probabilities, has been researched extensively to examine the degree to which human choice conforms to, or departs from, what would be normatively rational in terms of choices maximising some positive outcome, or 'expected value', over the longer term (Kahneman and Tversky, 1979; Tversky and Kahneman, 1992). The 'expected value' of a gamble is the sum of its component values (gains and losses), each weighted by its probability of occurrence. The expected value of the above two gambles is $(0.25 \times 100)+(0.75 \times-20)=10$ and $(0.25 \times 240)+(0.75 \times$ $-60)=15$. Thus, the normatively rational choice, in terms of maximising value over the longer term according to standard expected value theory (see Goldstein and Hogarth, 1997) would be the latter of these two gamble.

Two well-known examples of violations of normative decision-making include risk-averse choices when choosing between gain, and risk-seeking choices when choosing between losses. For example, most volunteers will choose a $100 \%$ chance of a gain of $\$ 40$ over a $50 \%$ chance of an $\$ 80$ and a $50 \%$ chance of nothing (indicating risk-aversion for gains), but choose a $50 \%$ chance of an $\$ 80$ loss and a $50 \%$ chance of no loss over a $100 \%$ chance of a loss of $\$ 40$ (indicating risk-seeking for losses) (Kahneman and Tvers$\mathrm{ky}, 1979$ ). Notice that the 'expected value' of each gamble in both of these pairs is equal, predicting that volunteers should be indifferent to the options (Kahneman and Tversky, 1979). In the present study, we have adapted these techniques in a procedure that allows us to assess the impact of reduced tryptophan on separable factors known to be involved in human decision-making: the magnitude of expected gains (or reward), the magnitude of expected losses (or punishment), and the probabilities with which each of these outcomes will be delivered. We also incorporated separate conditions to test the effects of tryptophan depletion on choices between gambles driven by risk-aversive (gains) and -seeking (losses) biases.

\section{METHODS}

The study was approved by the Oxfordshire Psychiatric Research Ethics Committee (OPREC). All volunteers provided written informed consent.

\section{Subjects}

In all, 36 healthy volunteers participated. Each volunteer was examined by a psychiatrist (ZB) to ensure that neither of the following exclusion criteria was met: (i) major physical illness; (ii) a history of DSM-IV depressive illness as assessed by an SCID-I interview. (Note: a family history of depression was not an exclusion criterion.) Verbal intelligence was assessed with the National Adult Reading Test (NART; Nelson, 1982). 


\section{Design}

The study was a double-blind, placebo-controlled design. A total of 18 volunteers were administered an amino-acid drink without tryptophan (the T- group) and 18 volunteers were administered an amino-acid drink with tryptophan (the $\mathrm{T}+$ group).

\section{Procedure}

All volunteers followed a low-protein diet (less than $20 \mathrm{~g}$ total) the day before the study and then fasted overnight. Volunteers attended the laboratory at 8.30 am on the day of the study. Blood samples $(15 \mathrm{ml})$ were taken at this time to obtain baseline levels of total plasma tryptophan. Volunteers then drank an amino-acid drink over a 60 -min period. The composition of the drinks was (for males and females, respectively): L-alanine $(5.5 \mathrm{~g}, 4.58 \mathrm{~g})$; L-arginine $(4.9 \mathrm{~g}$, $4.08 \mathrm{~g})$; L-cysteine $(2.7 \mathrm{~g}, 2.25 \mathrm{~g})$; glycine $(3.2 \mathrm{~g}, 2.25 \mathrm{~g})$; L-histidine $(3.2 \mathrm{~g}, \quad 2.67 \mathrm{~g})$; L-isoleucine $(8.0 \mathrm{~g}, 6.67 \mathrm{~g})$; L-leucine $(3.5 \mathrm{~g}, 11.25 \mathrm{~g})$; L-lysine monohydrochloride $(11.0 \mathrm{~g}, 9.17 \mathrm{~g})$; L-methionine $(3.0 \mathrm{~g}, 2.5 \mathrm{~g})$; L-phenylalanine $(5.7 \mathrm{~g}, 4.75 \mathrm{~g})$; L-proline $(12.2 \mathrm{~g}, 10.17 \mathrm{~g})$; L-serine $(6.9 \mathrm{~g}$, $5.75 \mathrm{~g})$; L-threonine (6.5 g, $5.42 \mathrm{~g})$; L-tyrosine $(6.9 \mathrm{~g}, 5.75 \mathrm{~g})$; L-valine $(8.9 \mathrm{~g}, 7.42 \mathrm{~g})$. All amino acids were supplied by SHS International. None of the volunteers reported any side effects beyond transitory nausea. Volunteers were also given a low-protein (less than $2 \mathrm{~g}$ total) lunch at midday. A second blood sample was taken $5 \mathrm{~h}$ after consumption of the amino-acid drink $(+5 \mathrm{~h})$ in order to assess reductions in total plasma tryptophan. All volunteers then completed the computerised decision-making task.

Additionally, $16 \mathrm{~T}+$ and $14 \mathrm{~T}-$ volunteers completed psychometric assessments of state positive and negative affects (PANAS; Watson et al, 1988a) at baseline and at $+5 \mathrm{~h}$ after consumption of the amino-acid drinks. This information was used to assess the relationship between the effects of tryptophan depletion on decision-making and any effects on the mood of the volunteers (see Moore et al, 2000).

\section{Decision-Making Task}

Each trial required volunteers to choose to play one of the two simultaneously presented gambles. Each gamble was represented visually by a histogram, the height of which indicated the relative probability of gaining a given number of points. The expected gains were indicated in green ink above the histogram, while the expected losses were indicated in red ink underneath the histogram. On each trial, one gamble (coloured yellow) was always the control gamble, consisting of a $50 \%$ probability of winning 10 points and a $50 \%$ probability of losing 10 points (see Figure 1a). The alternative 'experimental' gamble (coloured blue) varied in the probability of winning which was either high or low (75 vs 25\%), the expected gains which were either large or small ( 80 vs 20 points), and the expected losses which were either large or small (80 vs 20 points). The combination of these variables, in a completely crossed design, resulted in eight trial types (see Table 1). Figure 1a shows an 'experimental' gamble with a $25 \%$ chance of winning 80 points (and a $75 \%$ chance of losing 20 points). a

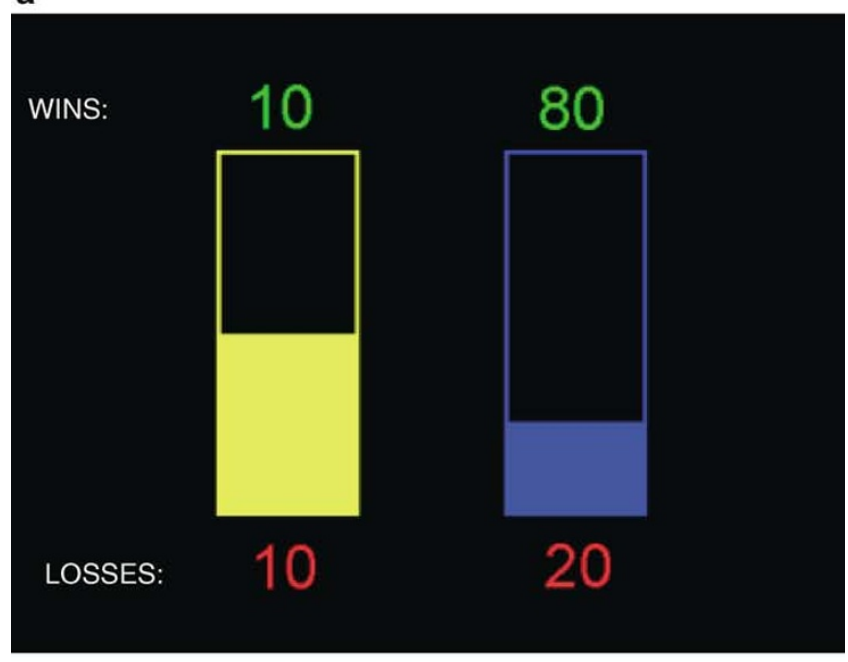

b

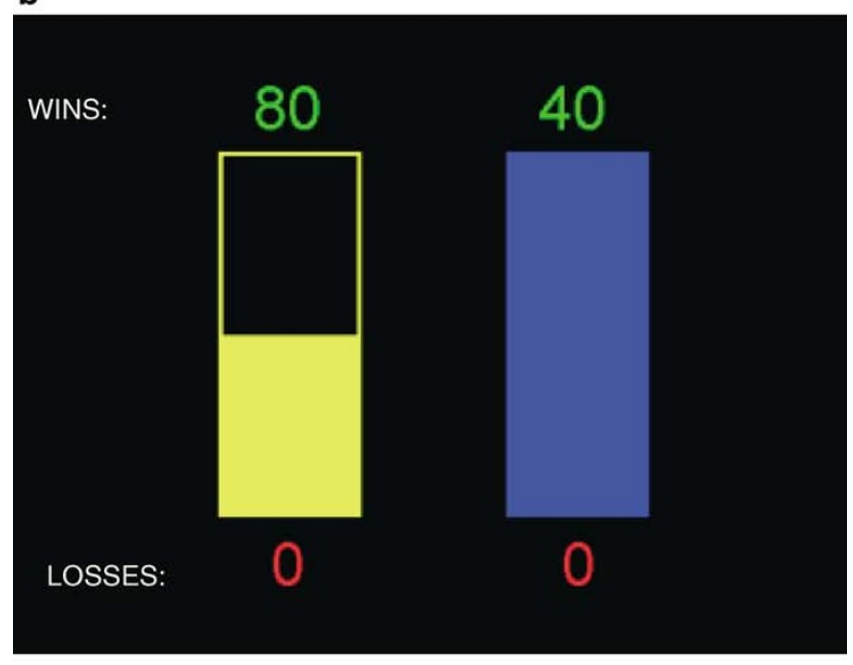

c

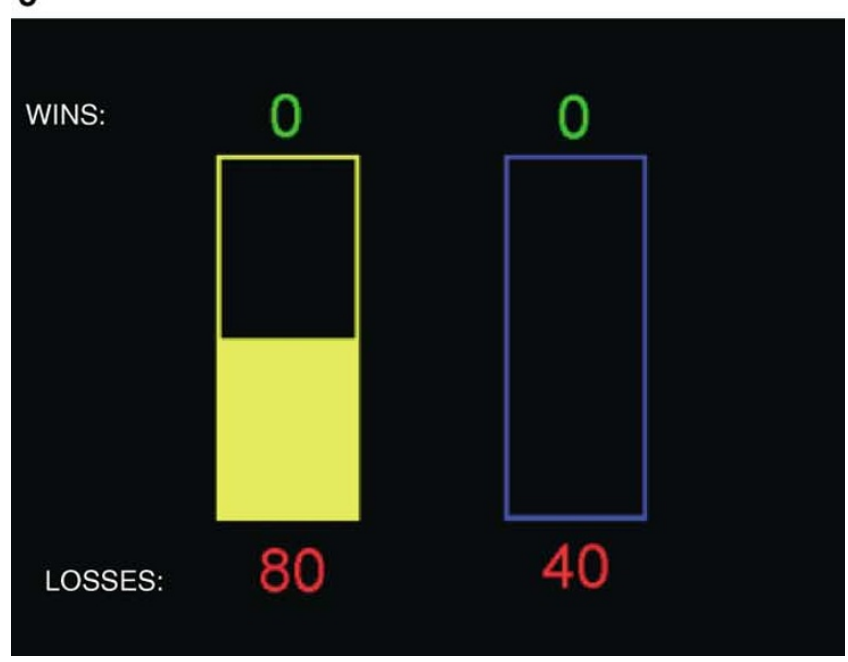

Figure I (a) One trial from the decision-making task consisting of an 'experimental' gamble with a $25 \%$ chance of winning 80 points and a $75 \%$ chance of losing 20 points vs the control gamble with a $50 \%$ chance of winning 10 points and a $50 \%$ of losing 10 points. (b) A 'gains only' trial from the decision-making task consisting of a certain win of 40 points vs $50 \%$ chance of winning 80 or 0 points. (c) A 'losses only' trial consisting of a certain loss of 40 points vs a $50 \%$ chance of a loss of 80 or 0 points. 
Table I Eight Types of 'Experimental' Gamble Resulting from the Combination, in a Completely Crossed Design, of Two Levels of Probability, Expected Gains, and Expected Losses

\begin{tabular}{lll}
\hline Probability & Expected gains & Expected losses \\
\hline High $(0.75)$ & Large $(80)$ & Large $(80)$ \\
& & Small $(20)$ \\
& Small $(20)$ & Large $(80)$ \\
Low $(0.25)$ & & Small $(20)$ \\
& Large $(80)$ & Large $(80)$ \\
& & Small $(20)$ \\
& Small $(20)$ & Large $(80)$ \\
& & Small $(20)$ \\
\hline
\end{tabular}

The control gamble and the 'experimental' gamble appeared randomly on the left or right of the display. The volunteer was required to press the ' 1 ' or the ' 2 ' key on a standard computer keyboard to indicate choice of the gamble presented on the left or the right. The dependent measure was the proportion of choices of the 'experimental' over the control gamble as a function of the combination of probability, the size of expected gains, and the size of the expected losses in the 'experimental' gamble. We also measured volunteers' discrimination between differences in probability, gains, and losses by calculating the absolute difference between the proportion of choices of the 'experimental' gamble over the control gamble when each of these factors was high (eg when the expected losses were large) and the proportion of choices of the 'experimental' gamble when that factor was low (eg when the expected losses were small).

In addition, we included two extra trial types that represented choices between gambles known to be subject to the non-normative biases of risk-aversion and riskseeking behaviour described earlier (Kahneman and Tversky, 1979). The first type was a 'gains only' trial in which volunteers were presented simultaneously with a guaranteed win of 40 points or a $50 \%$ chance of winning 80 points. Neither option involved any associated losses (see Figure 1b). By contrast, in the 'losses only' trial type, volunteers were presented simultaneously with a guaranteed loss of 40 points or a $50 \%$ chance of losing 80 points. Neither option offered any associated gains (Figure 1c). For the 'gains only' and 'losses only' trials, the dependent measure was the proportion of choices on which volunteers chose the guaranteed outcome.

All 10 trial types were presented pseudorandomly within four blocks. At the beginning of each block, volunteers were given 100 experimenter-defined points, and asked to make choices that would increase this amount by as much as possible. These points had no monetary value. Visual feedback was given after each choice and the revised points total was presented for $2 \mathrm{~s}$ before the next trial. Across the four blocks, there were eight repetitions of each 'experimental' gamble and eight repetitions of the 'gains only' and 'losses only' trial types.

\section{Analysis}

All the data were analysed with SPSS (Version 9.0; SPSS Inc., Cary, NC). The dependent measures of the decision-making task were the proportions of trials on which volunteers chose the 'experimental' over the control gamble ('proportionate choice'), and the mean deliberation time (ms) associated with their choices. The proportionate choices were arcsine-transformed, as is appropriate whenever the variance of a measure is proportional to its mean (Howell, 1987); however, all of the data reported in the text, figures, and tables describe untransformed values. The results were analysed using a single repeated measures analysis of variance (ANOVA), with the between-subject factors of group $(\mathrm{T}+v s \mathrm{~T}-$ ) and gender (male $v s$ female), and the within-subject factors of probability (high versus low), expected gains (large versus small), and expected losses (large $v s$ small). Discrimination measures for the three factors were analysed by separate ANOVAs, with group as a single between-subjects factor. The 'gains only' and 'losses only' trials were analysed with group and gender as between-subject factors and trial type ('gains only' $v s$ 'losses only') as a single within-subject factor.

\section{RESULTS}

The $\mathrm{T}+$ and $\mathrm{T}-$ volunteers were perfectly matched in terms of gender (nine males and nine females in each group) and were well matched in terms of age $(F[1,32]=0.36, p=0.55)$ and estimated verbal IQ $(\mathrm{F}[1,34]=0.05, p=0.83)$ (see Table 2). Total plasma tryptophan was significantly reduced in the $\mathrm{T}$ - volunteers over the $5 \mathrm{~h}$ following consumption of the amino-acid drink $(\mathrm{F}[1,16]=425.71, p<0.0001)$, but increased in the $\mathrm{T}+$ volunteers $(\mathrm{F}[1,16]=81.39, p<0.0001)$. (A verbal IQ score was unavailable for one $\mathrm{T}-$ volunteer; one pair of baseline and $+5 \mathrm{~h}$ plasma samples was unavailable for one $\mathrm{T}-$ volunteer; and one $+5 \mathrm{~h}$ plasma sample was unavailable for one $T+$ volunteer). Critically, at $+5 \mathrm{~h}$, the total plasma tryptophan of the $\mathrm{T}-$ volunteers was significantly lower than that of the $\mathrm{T}+$ volunteers $(\mathrm{F}[1$, $32]=352.79, p<0.0001)$.

\section{Probability, Wins, and Losses}

Proportionate choice In general, volunteers chose the 'experimental' gamble significantly more often when its probability of winning was high compared to when it was low $(F[1,32]=128.27, p<0.0001)$ (see Figure 2a). There was no evidence that this pattern of choice was changed in the $\mathrm{T}$ - compared to the $\mathrm{T}+$ volunteers $(\mathrm{F}[1,32]=0.38$, $p=0.54)$. Similarly, volunteers chose the 'experimental' gamble significantly less often when its expected losses were large compared to when its expected losses were small ( $\mathrm{F}[1$, $32]=44.97, p<0.0001)$, and to a similar extent in both groups $(F[1,32]=0.29, p=0.59$ ) (see Figure $2 b$ ). However, while all the volunteers chose the 'experimental' gamble more often when its expected gains were large compared to when they were small $(F[1,32]=97.67, p<0.0001)$, this pattern of decision-making was significantly attenuated in the $\mathrm{T}$ - compared to the $\mathrm{T}+$ volunteers $(\mathrm{F}[1,32]=6.1$, $p<0.02$ ) (see Figure 2c). Additional analysis showed that both groups of volunteers showed comparable discrimination between different probabilities of winning ( $\mathrm{F}[1$, $32]=0.54, p=0.47$ ), and between different magnitudes of expected losses $(\mathrm{F}[1,32]=0.37, p=0.55)$, but that the $\mathrm{T}-$ volunteers showed significantly less discrimination than $\mathrm{T}+$ 
Table 2 Demographic Details (mean \pm standard error) of Volunteers who Consumed an Amino Acid with $(T+)$ and without $(T-)$ LTryptophan, and total plasma tryptophan (TRP) $(\mu \mathrm{g} / \mathrm{ml})$ at baseline and at $+5 \mathrm{~h}$

\begin{tabular}{llllll}
\hline Group & M/F & Age (years) & Verbal IQ & $\begin{array}{l}\text { Plasma total TRP } \\
\text { at } \mathbf{~} \mathbf{h}(\boldsymbol{\mu g} / \mathbf{m l})\end{array}$ & $\begin{array}{l}\text { Plasma total } \\
\text { TRP at }+\mathbf{5} \mathbf{h}^{\mathbf{a}}(\boldsymbol{\mu g} / \mathbf{m l})\end{array}$ \\
\hline$T+$ & $9 / 9$ & $23.4 \pm 0.9$ & $113.6 \pm 1.1$ & $12.0 \pm 0.5$ & $21.4 \pm 1.0$ \\
$T-$ & $9 / 9$ & $24.2 \pm 1.0$ & $114.0 \pm 1.7$ & $13.2 \pm 0.6$ & $2.3 \pm 0.2$ \\
\hline
\end{tabular}

aroup (T+vs T-): F[1, 32] $=352.79, p<0.0001$.
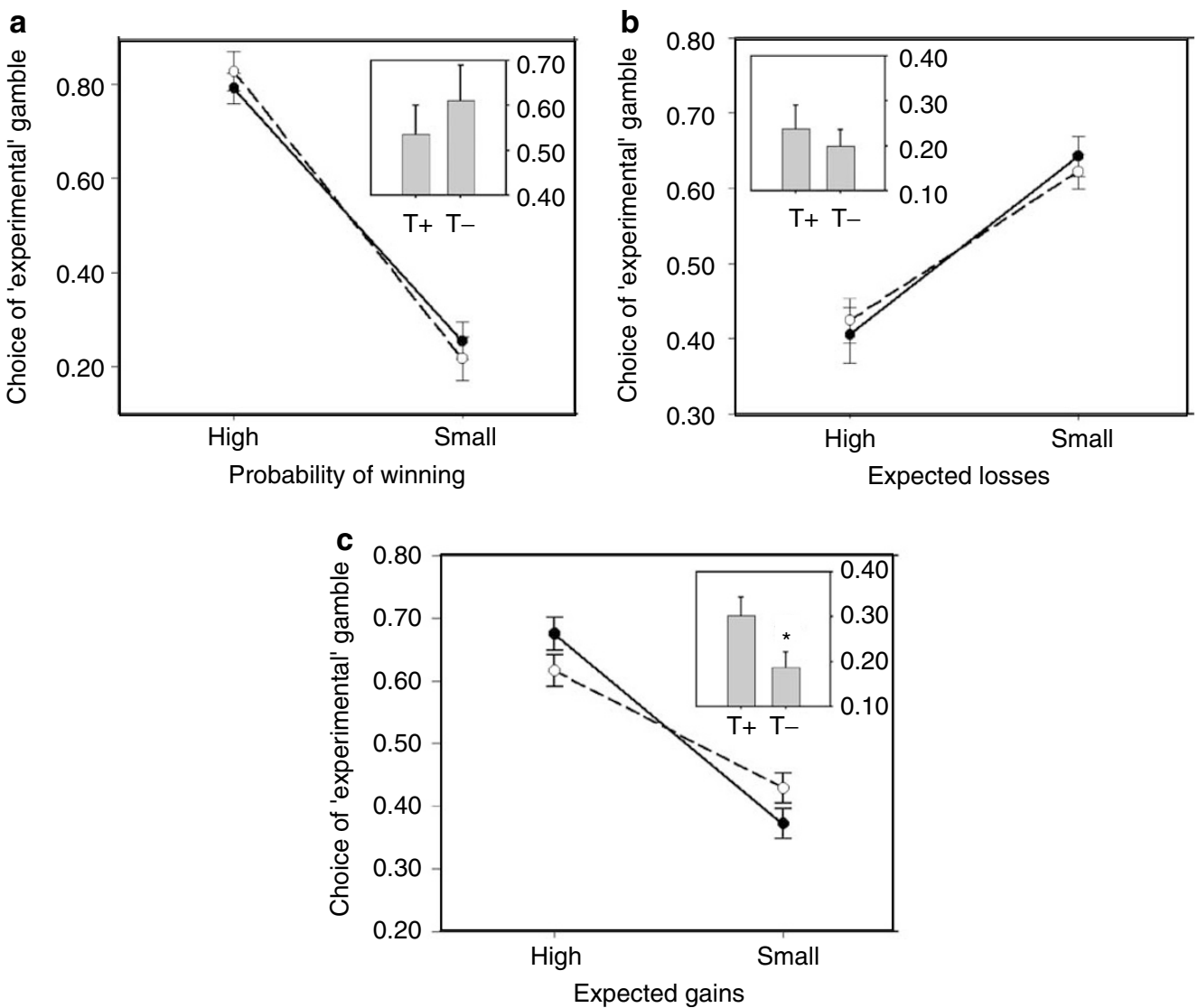

Figure 2 Proportion of choices of the 'experimental' over the control gamble by the $T+$ and $T$ - volunteers for the three manipulated factors: (a) high vs low probability of winning (inset the mean difference between the proportions of choices of the 'experimental' over the control gamble when its probability of winning was high and the proportions of choices of the 'experimental' gamble when its probability of winning was low); (b) large vs small losses (inset the mean difference between the proportions of choices of the 'experimental' gamble over the control gamble when its expected losses were large and the proportions of choices of the 'experimental' gamble when its expected losses were small); (c) large vs small gains. Group (T+vs $T-$ volunteers) $\times$ expected gains (large vs small): $\mathrm{F}[\mathrm{I}, 32]=6.07, p<0.02$ (inset the mean difference between the proportions of choices of the 'experimental' over the control gamble when its expected gains were large and the proportions of choices when its gains were small; *F $[1,34]=4.98, p<0.05)$.

volunteers between different magnitudes of expected gains $(\mathrm{F}[1,32]=4.98, p<0.04)$, (see Figure $2 \mathrm{c}$, inset).

Subsidiary analyses of the data from the $16 \mathrm{~T}+$ volunteers and the $14 \mathrm{~T}$ - volunteers who completed psychometric measures of state positive and negative affect confirmed that the reduced discrimination between magnitudes of expected gains in the decision-making of the $\mathrm{T}$ - volunteers compared to the $\mathrm{T}+$ volunteers was not dependent upon gross changes in mood induced by tryptophan depletion. In both sets of volunteers, positive affect declined significantly in the $5 \mathrm{~h}$ following consumption of the drink ( $\mathrm{F}[1$, $26]=6.19, p<0.03)$ (Table 3), but no more so for $\mathrm{T}-$ than for $\mathrm{T}+$ volunteers $(\mathrm{F}[1,26]=1.57, p=0.22)$. Negative affect did not change significantly over this time $(F[1,26]=0.56$, $p=0.46)$. Crucially, there were no significant differences between the $\mathrm{T}-$ and $\mathrm{T}+$ volunteers in positive or negative affects at cognitive testing $(\mathrm{F}[1,28]=0.67, p=0.42$ and $\mathrm{F}[1$, $28]=0.38, p=0.54$, respectively).

Despite closely matched state affect in these volunteers, the increased choice of the 'experimental' gamble when its expected gains were large relative to when they were small remained significantly attenuated in the $\mathrm{T}-$ compared to the $\mathrm{T}+$ volunteers $(\mathrm{F}[1,26]=10.92, p<0.005)$. Analysis of the simple effects indicated that the $\mathrm{T}-$ volunteers chose the 'experimental' gamble significantly less often than the $\mathrm{T}+$ volunteers when its gains were large $(\mathrm{F}[1,26]=6.36$, $p<0.02$ ) (Table 3). Moreover, the $\mathrm{T}-$ volunteers exhibited significantly reduced discrimination between different 
Table 3 State Positive and Negative Affect (PANAS; Watson et al, 1988a), and the Proportion of Choices of the 'Experimental' over the Control Gamble in Healthy Volunteers who Consumed an Amino-acid Drink with $(T+; n=16)$ and without (T-; $n=14)$ L-Tryptophan

\begin{tabular}{|c|c|c|c|c|c|c|}
\hline \multirow[b]{2}{*}{ Group } & \multirow{2}{*}{$\begin{array}{l}\text { State +ve } \\
\text { affect at } 0 \mathrm{~h}\end{array}$} & \multirow{2}{*}{$\begin{array}{l}\text { State }- \text { ve } \\
\text { affect at } 0 \mathrm{~h}\end{array}$} & \multirow{2}{*}{$\begin{array}{l}\text { State }+v e \\
\text { affect at }+5 h\end{array}$} & \multirow{2}{*}{$\begin{array}{l}\text { State }-v e \\
\text { affect at }+5 h\end{array}$} & \multicolumn{2}{|c|}{$\begin{array}{l}\text { Prop. of choice of experimental } \\
\text { gamble for two levels of expected gains }\end{array}$} \\
\hline & & & & & Large $^{b}$ & Small \\
\hline $\mathrm{T}+$ & $27.4 \pm 1.4$ & $10.8 \pm 0.4$ & $26.0 \pm 1.7$ & $10.6 \pm 0.4$ & $0.69 \pm 0.03$ & $0.36 \pm 0.03$ \\
\hline$T_{-}$ & $28.7 \pm 1.5$ & $11.1 \pm 0.3$ & $24.4 \pm 1.8$ & $10.9 \pm 0.4$ & $0.61 \pm 0.03$ & $0.43 \pm 0.03$ \\
\hline
\end{tabular}

Table 4 Mean Deliberation Times (ms) as a Function of High and Low Levels of Probability of Winning, High and Low Levels of Expected Losses and Expected Gains in Healthy Volunteers Who Consumed an Amino-Acid Drink with $(T+; n=16)$ and without $(T-; n=14)$ L-Tryptophan

\begin{tabular}{|c|c|c|c|c|c|c|}
\hline \multirow[b]{2}{*}{ Group } & \multicolumn{2}{|c|}{$\begin{array}{l}\text { Probability of winning on } \\
\text { the 'experimental' gamble }\end{array}$} & \multicolumn{2}{|c|}{$\begin{array}{l}\text { Levels of expected losses } \\
\text { on 'experimental' gamble }\end{array}$} & \multicolumn{2}{|c|}{$\begin{array}{l}\text { Levels of expected gains } \\
\text { on 'experimental' gamble }\end{array}$} \\
\hline & High & Low & Large & Small & Large & Small \\
\hline $\begin{array}{l}\mathrm{T}+ \\
\mathrm{T}-\end{array}$ & $\begin{array}{l}1760 \pm 161 \\
1414 \pm 87\end{array}$ & $\begin{array}{l}2066 \pm 168 \\
1718 \pm 128\end{array}$ & $\begin{array}{l}1972 \pm 167 \\
1654 \pm 119\end{array}$ & $\begin{array}{l}1854 \pm 170 \\
1478 \pm 92\end{array}$ & $\begin{array}{l}1848 \pm 150 \\
1523 \pm 110\end{array}$ & $\begin{array}{l}1978 \pm 179 \\
1609 \pm 101\end{array}$ \\
\hline
\end{tabular}

aProb. of winning on 'experimental gamble' (large vs small): $F[I, 32]=35.23, p<0.000 \mathrm{I}$. 'Level of expected losses (large vs small): $F[I$, $32]=7.29, p<0.02$. 'Level of expected gains (large vs small): $F[I, 32]=6.32, p<0.02$.

magnitudes of expected gains associated with the 'experimental' gamble compared to the $\mathrm{T}+$ volunteers ( $\mathrm{F}[1$, $28]=7.19, p<0.02)$, but a similar discrimination between different probabilities $\mathrm{F}[1,28]=0.69, p=0.41)$ and magnitudes of losses $\mathrm{F}[1,28]=0.53, p=0.47)$. Finally, entering state positive and negative affect of measures at cognitive testing as covariates into the analysis left the central result unchanged; that is, the $\mathrm{T}-$ volunteers showed attenuated choice of the 'experimental' gamble over the control gamble as a function of the size of its expected gains ( $\mathrm{F}[1$, $24]=10.20, p<0.005)$.

Overall, male volunteers tended to choose the 'experimental' gamble slightly less often than female volunteers $(0.50 \pm 0.02$ vs $0.55 \pm 0.02)(\mathrm{F}[1,32]=4.21, p<0.05)$. There were no significant interactions involving gender and any task variable or/and treatment group. Repeat analyses, including age and estimated verbal IQ as covariates, indicated that age tended to covary with choice of the 'experimental' gamble $(\mathrm{F}[1,28]=4.03, p=0.06)$ and, in particular, with the reduction in choice of the 'experimental' gamble associated with larger compared to smaller losses $(\mathrm{F}[1,28]=4.58, p<0.05)$. Finally, estimated verbal IQ was not a significant covariate of choice of the 'experimental' gamble $(\mathrm{F}[1,28]=2.68, p=0.11)$.

Deliberation times Volunteers were significantly faster to make their choices when the probability of winning on the 'experimental' gamble was high compared to when it was low $(\mathrm{F}[1,32]=35.23, p<0.0001)$. This effect was not greater in the $\mathrm{T}-$ volunteers compared to the $\mathrm{T}+$ volunteers $(\mathrm{F}[1$, 32 ] $<0.001, p=0.98$ ) (see Table 4). All volunteers made significantly slower choices when the 'experimental' gamble was associated with large expected losses compared to small expected losses $(F[1,32]=7.29, p<0.02)$, but significantly faster choices when it was associated with large expected gains compared to small expected gains $(F[1,32]=6.32$, $p<0.02)$. Neither of these effects were significantly altered in the $\mathrm{T}-$ volunteers compared to the $\mathrm{T}+$ volunteers $(\mathrm{F}[1$, $32]=0.28, p=0.60)$ and $\mathrm{F}[1,32]=0.27, p=0.61$, respectively). Overall, the $\mathrm{T}-$ volunteers tended to make their choices faster than the $\mathrm{T}+$ volunteers $(1566 \pm 102$ vs $1913 \pm 161 \mathrm{~ms}) \quad(\mathrm{F}[1,32]=3.30, p=0.08)$, as did male compared to female volunteers $(1557 \pm 117 \quad v s$ $1922 \pm 151 \mathrm{~ms})(\mathrm{F}[1,32=3.66, p=0.07)$.

Repeat analyses of the mean deliberation times including state positive and negative affect measured at $+5 \mathrm{~h}$ following consumption of the amino-acid drink, or age and estimated verbal IQ, as covariates did not reveal any significant interactions involving treatment group or probability of winning on the 'experimental' gamble or the size of expected gains or losses.

\section{'Gains Only' vs 'Losses Only' Trials}

Proportionate choice Volunteers overwhelmingly chose the guaranteed outcome significantly more often on the 'gains only' trials (offering a choice between a certain gain of 40 points and a $50 \%$ chance of 80 or 0 points) than on the 'losses only' trials (offering a certain loss of 40 points or a $50 \%$ chance of a loss of 80 or 0 points $)(F[1,32]=90.54$, $p<0.0001$ ) (Figure 3). However, this pattern of choices (risk-aversion when choosing between gains and riskseeking when choosing between losses) was not significantly different in the $\mathrm{T}-$ volunteers compared to the $\mathrm{T}+$ volunteers $(F[1,32]=0.88, p=0.36)$.

Deliberation times Volunteers were significantly quicker to make their choices on the 'gains only' trials compared to 


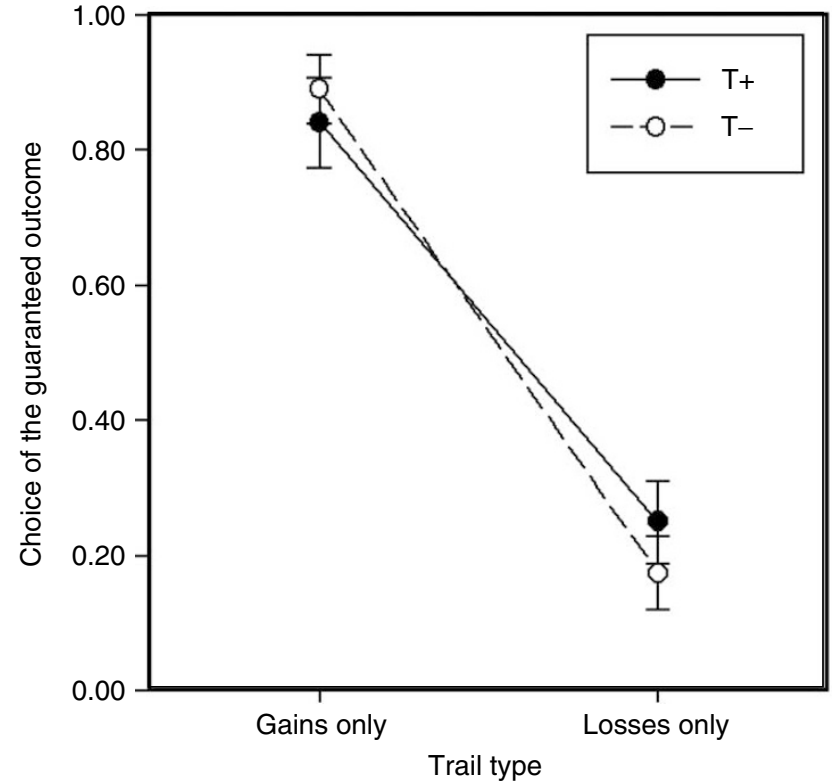

Figure 3 Proportion of choices of the guaranteed outcome by the T+ and $T-$ volunteers for the 'gains only' trials and the 'losses only' trials.

the 'losses only' trials $(\mathrm{F}[1,32]=41.78, p<0.0001)$, with no difference in the size of this effect in the $\mathrm{T}-$ volunteers $(1305 \pm 149$ vs $2689 \pm 407 \mathrm{~ms})$ compared to $\mathrm{T}+$ volunteers $(1622 \pm 214$ vs $2871 \pm 333 \mathrm{~ms})(\mathrm{F}[1,32]=0.11, p=0.74)$.

\section{DISCUSSION}

These data suggest that rapid dietary depletion of tryptophan-reducing central serotonin function (Nishizawa et al, 1997) - alters decision-making in healthy volunteers by attenuating their discrimination between different magnitudes of expected gains. There was little evidence that tryptophan depletion had any similar effects on volunteers' discrimination between magnitudes of expected losses, or differences in the probabilities with which each of these outcomes were delivered. Moreover, analyses of the data from those volunteers who completed ratings of positive and negative affect suggest that this selective effect on reward processing was not driven by gross changes in mood associated with tryptophan depletion. While volunteers who underwent tryptophan depletion $(\mathrm{T}-)$ and those who did not $(\mathrm{T}+)$ reported some reduction in positive affect between baseline and cognitive testing, this effect was not significantly greater in the $\mathrm{T}-$ compared to the $\mathrm{T}+$ volunteers, and most probably reflects the nonspecific changes in mood experienced across the experimental session. In essence, our results suggest that lowered central serotonergic function alters the decision-making of healthy volunteers principally by altering the processing of reward cues - in this case, reducing the discrimination between small and large rewards - rather than by any obvious effects on the processing of punishment cues or probabilistic cues.

The finding that tryptophan depletion alters the choices of healthy volunteers by reducing their discrimination between magnitudes of reward is consistent with the evidence that serotonin plays a significant role in modulating reward and incentive motivational processes, possibly through the modulation of the mesolimbic dopamine system (Baumgarten and Grozdanovic, 1995). SSRI treatment has been found to dose-dependently modulate brainstimulation reward thresholds via 5-HT1A receptors (Harrison and Markou, 2001a, b), and to potentiate the stimulant effects of cocaine (Cunningham and Callahan, 1991; Kleven and Koek, 1998). The role of serotonin in reinforcement is also evidenced by the finding that low doses of cocaine block the serotonin transporter more potently than the dopamine transporter (Ritz and Kuhar, 1987), and by the demonstration that both these transporters appear necessary for cocaine's rewarding effects in a conditioned place preference procedure (Sora et al, 2001).

More directly, tryptophan depletion has been shown to diminish the euphoric effects of intravenous cocaine in cocaine addicts (Aronson et al, 1995), and to reduce the craving experienced when presented with cocaine-related paraphernalia (Satel et al, 1995). The latter finding suggests that serotonin affects the way that reward-associated signals influence behaviour; consistent with reports that fluoxetine potentiates the control of ongoing responding by available conditioned reinforcers (Sasaki-Adams and Kelley, 2001; Fletcher et al, 1999). In this context, it is important to note that the results of the present study do not, in themselves, show that tryptophan depletion reduces sensitivity to reward per se rather the data indicate that the $\mathrm{T}$ - volunteers did not discriminate as effectively as the $\mathrm{T}+$ volunteers between differences in the magnitude of rewards associated with different choices. Further research will be needed to discover whether this effect is best characterised as involving the attenuated impact of conditioned signals that predict reward or, alternatively, reduced sensitivity to reward itself. Nevertheless, although the effects of serotonin on dopaminergic tone and associated rewardbased processing are likely to be highly complex (SasakiAdams and Kelley, 2001), the present data do at least suggest that a generalised reduction in central serotonin function undermines decision-making in healthy volunteers by altering the processing of reward-related information when choosing between behavioural options.

As discussed above, several studies employing both lesion and electrophysiological techniques have shown that the capacity to learn stimulus-reward associations - as exemplified by visual discrimination and reversal-learning tasks - depends upon circuitry encompassing the orbitofrontal cortex (Dias et al, 1996; Jones and Mishkin, 1972; Thorpe et al, 1983). Additionally, decision-making involving choices between uncertain rewards and punishments is widely thought to involve the functioning of this same portion of the prefrontal cortex (Bechara et al, 1996; Damasio, 1994; Rogers et al, 1999b, c) while, most recently, Breiter et al (2001) have reported that the 'expected value' of monetary outcomes delivered noncontingently to healthy volunteers was associated with increased neural activity within the orbitofrontal cortex and its interconnected neural circuitry. The demonstrations that tryptophan depletion undermines both reversal learning in healthy volunteers (Park et al, 1994; Rogers et al, 1999a) and decision-making through the processing of reward information in the current study suggest that serotonin has a 
significant modulatory function in the affective processing associated with the orbitofrontal cortex.

All volunteers showed a significant reduction in the 'experimental' gamble when the expected losses were large compared to when they were small, suggesting that their choices were influenced by differences in the magnitude of expected punishments. However, there was no sign that the size of this effect was greater in the $\mathrm{T}$ - compared to the $\mathrm{T}+$ volunteers. This result may seem surprising in view of serotonin's proposed role in the modulation of anxiety (Deakin and Graeff, 1991; Gray, 1987; Iversen, 1984), and the specific proposal that serotonergic activity mediates anticipatory anxiety states activated by aversive stimuli (Deakin and Graeff, 1991; Melik et al, 2000; Tye et al, 1977; Wilkinson et al, 1995). Of course, the involvement of serotonin in mediating anxiety remains controversial with, for example, continuing difficulties in demonstrating impaired conditioning to discrete stimuli as opposed to contextual stimuli following serotonin depletions (Mansbach and Geyer, 1988; Wilkinson et al, 1995). However, we suggest tentatively two factors that may account for the absence of altered decision-making through effects on the processing of punishment cues in this study.

First, it might have been that the sizes of the expected losses were too small to serve as effective punishment signals and engage sufficiently the serotonin system in the aversive aspect of the decision-making task. However, as against this, Figure $2 \mathrm{~b}$ and Table 4 clearly show that volunteers did find the prospect of large losses sufficiently aversive to induce them to reduce their choice of the 'experimental' gamble alongside a marked increase in the associated deliberation time. Second, the size of the smaller and larger rewards was matched perfectly with the size of the smaller and larger punishments $(20 \mathrm{vs} 80$ points in each case) so that the relative balance between approach and avoidant response tendencies activated by the gains and losses would have been roughly balanced across the trials. In this case, there may have been an insufficient requirement for inhibition of activated approach responses on the presentation of aversive cues consisting of large expected losses. Such an inhibitory operation might have been undermined by reduced central serotonin (Soubrie, 1986). We are currently exploring these possibilities.

The lack of an effect of tryptophan depletion on the processing of probabilistic cues is unsurprising in view of the evidence suggesting, for example, that 5,7-hydroxytryptamine- induced lesions in rats do not disrupt or change substantially the discounting of differences in the probability with which particular rewards are delivered (Mobini et al, 2000). However, in the present study, it was clear that both the $\mathrm{T}-$ and $\mathrm{T}+$ volunteers found the discrepancy between the low probability (25\%) and high probability (75\%) of reward and punishment in the 'experimental' gambles particularly large, perhaps reducing the sensitivity of this particular measure in detecting differences as the result of tryptophan depletion. Nevertheless, with this acknowledged caveat, we can conclude that the failure to find an effect of tryptophan depletion is at least consistent with the existing literature that serotonin function is not clearly implicated in the processing of probabilistic information.
Finally, the finding that the effects of reduced tryptophan on discrimination between the magnitudes of reward may have important clinical implications. Several theories have suggested that lowered mood and anhedonia in depression are associated with altered processing of reward (Lewinsohn and Graf, 1973) and a failure to activate appetitive responses upon presentation of reward cues (Henriques and Davidson, 1991; Henriques et al, 1994). Other researchers have linked depression explicitly with reduced positive affect measured psychometrically (Watson et al, 1988a); and depressive symptomatology, including difficulties in the experience of pleasure, to altered serotonergic modulation of dopamine function (Van Praag et al, 1987). The motivational/affective aspects of withdrawal phenomena have been linked to serotonergic reductions in limbic circuitry of drug-dependent individuals (Markou et al, 2001). In the present study, subsidiary analyses suggested that tryptophan depletion did not affect the way in which reward cues were processed in the context of decisionmaking through gross changes in positive or negative affect (Watson et al, 1988b). Nevertheless, tryptophan depletion in the $\mathrm{T}$ - volunteers did produce a cognitive and emotional state in which differences in the probability of outcomes and the magnitude of punishment associated with these outcomes loomed larger than differences in the magnitude of reward in the context of choices between competing courses of action. It is possible that this state, if prolonged, represents a precursor to lowered mood in vulnerable groups. Further research is needed to examine whether such alterations in the use of reward cues in decision-making are found in mood disorders, whether they represent traits or states associated with illness, and whether they can be remediated by upregulation of serotonin function.

\section{ACKNOWLEDGEMENTS}

Elizabeth $\mathrm{M}$ Tunbridge is supported by a Wellcome Trust Prize Scholarship (2000/2004). Zubin Bhagwagar is funded by an MRC Clinical Training Fellowship. We particularly thank Judi Wakeley of the University Department of Psychiatry, University of Oxford, for her help in completing the study.

\section{REFERENCES}

Aronson SC, Black JE, McDougle CJ, Scanley BE, Jatlow P, Kotsen TP et al (1995). Serotonergic mechanisms of cocaine effects in humans. Psychopharmacology (Berl) 19: 179-185.

Baumgarten HG, Grozdanovic Z (1995). Psychopharmacology of central serotonin systems. Pharmacopsychiatry 28 (Suppl): 73-79.

Bechara A, Dolan S, Denburg N, Hindes A, Anderson SW, Nathan PE (2001). Decision-making deficits, linked to a dysfunctional ventromedial prefrontal cortex, revealed in alcohol and stimulant abusers. Neuropsychologia 39: 376-389.

Bechara A, Tranel D, Damsio H, Damasio AR (1996). Failure to respond automatically to anticipated future outcomes following damage to prefrontal cortex. Cerebr Cortex 6: 215-225.

Breiter HC, Aharon I, Kahneman D, Dale A, Shizgal P (2001). Functional imaging of neural responses to expectancy and experience of monetary gains and losses. Neuron 30: 619-639. 
Critchley MAE, Njung'e K, Handley SL (1992). Actions and some interactions of some 5HT1A ligands in the elevated X-maze and effects of dorsal raphe lesions. Psychopharmacology 106: 484-490.

Cunningham KA, Callahan PM (1991). Monoamine reuptake inhibitors enhance the discriminative state induced by cocaine in the rat. Psychopharmacology (Berl) 104: 177-180.

Damasio AR (1994). Descartes'Error. Grosset/Pullman: New York. Deakin JFW, Graeff FG (1991). 5HT and mechanisms of defence. $J$ Psychopharmacol 5: 305-315.

Dias R, Robbins TW, Roberts AC (1996). Dissociation in prefrontal cortex of affective and attentional shifts. Nature 380: 69-72.

Fletcher PJ, Korth KM, Chambers JW (1999). Selective destruction of brain serotonin neurons by 5,7-dihydroxytryptamine increases responding for conditioned reward. Psychopharmacology 147: 291-299.

Goldstein WM, Hogarth RM (1997). Research on Judgment and Decision-Making. Currents, Connections and Controversies. Cambridge University Press: Cambridge, UK.

Gray JA (1987). The Neuropsychology of Anxiety: An Enquiry into the Functions of the Septo-hippocampal System. Oxford University Press: Oxford.

Harrison AA, Everitt BJ, Robbins TW (1997). Central 5-HT depletion enhances impulsive responding without affecting the accuracy of performance: interactions with dopaminergic mechanisms. Psychopharmacology (Berl) 133: 329-342.

Harrison AA, Everitt BJ, Robbins TW (1999). Central serotonin depletion impairs both the acquisition and performance of a symmetrically reinforced go/no go conditional visual discrimination. Behav Brain Res 100: 99-112.

Harrison AA, Markou A (2001a). Serotonergic manipulations both potentiate and reduce brain stimulation reward in rats: involvement of serotonin-1A receptors. J Pharmacol Exp Ther 297: 316-325.

Harrison AA, Markou A (2001b). Fluoxetine combined with a serotonin-1A receptor antagonist reversed reward deficits observed during nicotine and amphetamine withdrawal in rats. Neuropsychopharmacology 25: 55-71.

Henriques JB, Davidson RJ (1991). Left frontal hypoactivation in depression. J Abnorm Psychol 100: 535-545.

Henriques JB, Glowacki JM, Davidson RJ (1994). Reward fails to alter response bias in depression. J Abnorm Psychol 103: 460-466.

Howal DC (1987). Statistical Methods for Psychology. Pers Publishers: Boston, MA.

Iversen SD (1984). 5HT and anxiety. Neuropharmacology 23(12B): $1553-1560$.

Jones B, Mishkin M (1972). Limbic lesions and the problem of stimulus-reinforcement associations. Exp Brain Res 11: 376-386.

Kahneman D, Tversky A (1979). Prospect theory: an analysis of decision-making. Econometrica 47: 263-291.

Kleven MS, Koek W (1998). Discriminative stimulus properties of cocaine: enhancement by monoamine reuptake blockers. J Pharmacol Exp Ther 284: 1015-1025.

Lewinsohn PM, Graf M (1973). Pleasant activities and depression. J Consult Clin Psychol 41: 261-268.

Mansbach RS, Geyer MA (1988). Blockade of potentiated startle responding in rats by 5-hydroxytryptamine1 A receptor ligands. Eur J Pharmacol 156: 376-383.

Markou A, Kosten TR, Koob GF (2001). Neurobiological similarities in depression and drug dependence: a self-medication hypothesis. Neuropsychopharmacology 18: 135-174.

Melik E, Babar-Melik E, Ozgunen T, Binokay S (2000). Median raphe nucleus mediates forming long-term but not short-term contextual fear conditioning in rats. Behav Brain Sci 112: 145-150.

Mobini S, Chiang TJ, Ho MY, Bradshaw CM, Szabadi E (2000). Effects of central 5-hydroxytryptamine depletion on sensitivity to delayed and probabilistic reinforcement. Psychopharmacology (Berl) 152: 390-397.

Moore P, Landolt H-P, Seifritz, Clark C, Bhatti T, Kelsoe J et al (2000). Clinical and physiological consequences of rapid tryptophan depletion. Neuropsychopharmacology 23: 601-622.

Nelson HE (1982). National Adult Reading Test (NART) Test Manual. NFER-Nelson: Windsor, UK.

Nishizawa S, Benkelfat C, Young SN, Leyton M, Mzengeza S, de Montigny C et al (1997). Differences between males and females in rates of serotonin synthesis in human brain. Proc Nat Acad Sci USA 94: 5308-5313.

Park SB, Coull JT, McShane RH, Young AH, Sahakian BJ, Robbins TW et al (1994). Tryptophan depletion in normal volunteers produces selective impairments in learning and memory. Neuropharmacology 33: 575-588.

Parsons LH, Weiss F, Koob GF (1996). Serotonin1b receptor stimulation enhances dopamine-mediated reinforcement. Psychopharmacology (Berl) 128: 150-160.

Rahman S, Sahakian BJ, Cardinal RN, Rogers RD, Robbins TW (2001). Decision-making and neuropsychiatry. Trends Cognitive Neurosci 5: 271-277.

Ritz MC, Kuhar MJ (1987). Relationship between self-administration of amphetamine and monoamine receptors in brain: comparison with cocaine. J Pharmacol Exp Ther 248: 1010-1017.

Rogers RD, Blackshaw AJ, Middleton HC, Matthews K, Deakin JFW, Sahakian BJ et al (1999a). Tryptophan depletion impairs stimulus-reward learning while methylphenidate disrupts attentional control in healthy young adults: implications for the monoaminergic basis of impulsive behaviour. Psychopharmacology 146: 482-491.

Rogers RD, Everitt BJ, Baldacchino A, Blackmore AJ, Swainson R, London $\mathrm{M}$ et al (1999b). Dissociating deficits in the decisionmaking cognition of chronic amphetamine abusers, opiate abusers, patients with focal damage to prefrontal cortex, and tryptophan-depleted normal volunteers: evidence for monoaminergic mechanisms. Neuropsychopharmacology 20: 322-329.

Rogers RD, Owen AM, Middleton HC, Pickard J, Robbins TW (1999c). Decision-making in humans activates multiple sites within orbital prefrontal cortex: a PET study. J Neurosci 20: 9029-9038.

Sasaki-Adams DM, Kelley AE (2001). Serotonin-dopamine interactions in the control of conditioned reinforcement and motor behavior. Neuropsychopharmacology 25: 440-452.

Satel SL, Krystal JH, Delgado PL, Kosten TR, Charney DS (1995). Tryptophan depletion and attenuated craving for cocaine. Am J Psychiatry 152: 778-783.

Schildkraut JJ (1965). The catecholamine hypothesis of affective disorders: a review of supporting evidence. Am J Psychiatry 122: 509-522.

Smith KA, Fairburn CG, Cowen PJ (1997). Relapse of depression after rapid depletion of tryptophan. Lancet 349: 915-919.

Sora I, Hall FS, Andrews AM, Itokawa M, Li XF, Wei HB et al (2001). Molecular mechanisms of cocaine reward: combined dopamine and serotonin transporter knockouts eliminate cocaine place preference. Proc Natl Acad Sci USA 98: 5300-5305.

Soubrie P (1986). Reconciling the role of serotonin neurons in human and animal behaviour. Behav Brain Sci 9: 319-364.

Thorpe SJ, Rolls ET, Maddison S (1983). Neuronal activity in the orbitofrontal cortex of the behaving monkey. Exp Brain Res 49: 93-115.

Tversky A, Kahneman D (1992). Advances in prospect theory: cumulative representation of uncertainty. J Risk Uncertainty 5: 297-323.

Tye NC, Everitt BJ, Iversen SD (1977). 5-Hydroxytryptamine and punishment. Nature 268: 741-743.

Van Praag HM, Kahn RS, Asnis GM, Wetzler S, Brown SL, Bleich A et al (1987). Denosologization of biological psychiatry or the 
specificity of 5-HT disturbances in psychiatric disorders. J Affect Disord 13: 1-8.

Walsh SL, Cunningham KA (1997). Serotonergic mechanisms involved in the discriminative stimulus, reinforcing and subjective effects of cocaine. Psychopharmacology (Berl) 130: 41-58.

Watson D, Clark LA, Tellegen A (1988a). Development and validation of brief measures of positive and negative affect: The PANAS Scale. J Person Soc Psychol 54: 1063-1070.

Watson D, Clark LA, Tellegen A (1988b). Positive and negative affectivity and their relation to anxiety and depressive disorders. J Abnorm Psychol 97: 346-353.
Weiss F, Parsons LH, Schulteis G, Hyytia P, Bloom FE, Koob GF (1996). Ethanol self-administration restores withdrawal associated deficiencies in accumbal dopamine and 5-hydroxytryptamine release in dependent rats. $J$ Neurosci 16: 3474-3485.

Wilkinson LS, Humby T, Robbins TW, Everitt BJ (1995). Differential effects of forebrain 5-Hydroxytryptamine depletions on Pavlovian aversive conditioning to discrete and contextual stimuli in the rat. Eur $J$ Neurosci 7: 2042-2052. 